\title{
Degradation Behavior of Epoxy Resins in Fibre Metal Laminates Under Thermal Conditions
}

\author{
$Z H U$ Guo-liang ${ }^{1,2 *}$ (祝国梁), XIAO Yan-ping ${ }^{1,3 *}$ (肖艳萍), YANG Yong-xiang ${ }^{1,3,4}$ (杨永祥) \\ WANG Jun ${ }^{2}$ (王 俊), SUN Bao-de (孙宝德)，BOOM Rob ${ }^{1}$
}

(1. Department of Materials Science and Engineering, Delft University of Technology, 2628 CD Delft, The Netherlands; 2. State Key Laboratory of Metal Matrix Composites, Shanghai Jiaotong University, Shanghai 200240, China; 3. Department of Metallurgical Engineering, Anhui University of Technology, Ma'anshan 243002, Anhui, China; 4. Institute of Ferrous Metallurgy, Northeastern University, Shenyang 110819, China)

(C) Shanghai Jiaotong University and Springer-Verlag Berlin Heidelberg 2012

\begin{abstract}
GLARE (glass fibre/epoxy reinforced aluminum laminate) is a member of the fiber metal laminate (FML) family, and is built up of alternating metal and fiber layers. About $500 \mathrm{~m}^{2}$ GLARE is employed in each Airbus A380 because of the superior mechanical properties over the monolithic aluminum alloys, such as weight reduction, improved damage tolerance and higher ultimate tensile strength. Many tons of new GLARE scraps have been accumulated during the Airbus A380 manufacturing. Moreover, with the increasing plane orders of Airbus A380, more and more end-of-life (EOL) GLARE scrap will be generated after retire of planes within forty years. Thermal processing is a potential method for the material recycling and re-use from GLARE with the aim of environmental protection and economic benefits. The current study indicatdes that thermal delamination is a crucial pre-treatment step for the GLARE recycling. The decomposition behavior of the epoxy resins at elevated temperatures was investigated by using the simultaneous thermal analysis, thermogravimetry analysis (TGA) and differential scanning calorimetry (DSC). Based on the thermal analysis results, GLARE thermal delamination experiments at refined temperatures were carried out to optimize the treatment temperature and holding time. Key words: fibre metal laminates, GLARE (glass fibre/epoxy reinforced aluminum laminate), recycling, decomposition kinetics, thermal degradation
\end{abstract}

CLC number: TQ 316, V 252 Document code: A

\section{Introduction}

GLARE (glass fibre/epoxy reinforced aluminum laminate) is a member of the fibre metal laminate (FML) family, and it has been selected as the upper fuselage skin in superjumbo Airbus A380 because of excellent damage tolerance, fatigue resistance and their flame penetration resistance ${ }^{[1]}$. Weight saving of $10 \%$ is also an important advantage of GLARE compared with the monolithic aluminum alloys ${ }^{[1]}$, which is crucial to improve the fuel efficiency. Now, about $500 \mathrm{~m}^{2}$ GLARE is employed in each Airbus A380 ${ }^{[2]}$. With the increasing plane orders of Airbus A380, more end-of-life (EOL) GLARE scraps will be generated after retiring of planes within forty years. Moreover, many tons of new GLARE scraps have been accumulated during the Airbus A380 manufacturing, which have not been recycled.

Received date: 2012-03-22

Foundation item: the Royal Netherlands Academy of Science and Arts (KNAW) (No. 10CDP026), the National Outstanding Young Scientist Foundation of China (No. 50825401) and the National Natural Science Foundation of China (No. 50821003)

*E-mail: glzhu1983@hotmail.com, y.xiao@tudelft.nl
Recycling of both the manufacturing scraps and EOL scraps already becomes a relevant issue and should be seriously considered.

For the disposal of EOL fibre-reinforced composites, much of the composite waste currently produced is ultimately sent to landfill at present ${ }^{[3]}$, which is a poor solution for environmental impact, management of resources, and economic opportunity ${ }^{[4]}$. Thus it is very clear that turning the GLARE waste into a valuable resource is important for the continued use of the materials in some applications, depending on the compositions and properties of recycled materials. Thermal recycling is a practical solution for material recovery from GLARE scrap. GLARE thermal delamination depends to a large extent on the decomposition behavior of epoxy resins in it. Al sheets and glass fibres are separated after completely decomposing of epoxy resins; then Al alloys are recycled by melting and refining. Thermal analysis of epoxy resins under non-isothermal and isothermal conditions can determine the accurate process parameters for GLARE thermal delamination. The thermal decomposition behavior of epoxy resins at elevated temperature (non-isothermal condition) can 
provide significant information for the GLARE thermal delamination, e.g. initial decomposition temperature, end decomposition temperature, and relationship between decomposition degree and temperature under different heating rates.

In this paper, the decomposition behaviors and kinetics of epoxy resins in GLARE at elevated temperatures are studied by differential scanning calorimetry (DSC) and thermogravimetry analysis (TGA), and the heating rates vary from 1 to $5{ }^{\circ} \mathrm{C} / \mathrm{min}$. Both nitrogen and air atmospheres are considered respectively. At last, based on the thermal analysis results, GLARE thermal delamination experiments at refined temperatures are carried out to optimize the treatment temperature and holding time.

\section{Experimental Details}

\subsection{Materials}

The GLARE 3-8/7-(0.3-0.4) new scraps from Airbus
A380 window are used in this research work. The GLARE new scrap consists of 8 layers 2024-T3 aluminum alloy sheets coated with modified epoxy phenolic primer BR 127 on both surfaces of each sheet, bonded together with 7 layers of epoxy resin FM 94/S2glass fibre prepreg system ${ }^{[1,5]}$. The detailed structure of the GLARE scrap (http://gusnetwork.blogspot.com) is shown in Fig. 1. The total thickness of GLARE is $4.6 \mathrm{~mm}$. The $2024 \mathrm{Al}$ alloy sheet/BR 127 and FM 94/S2-glass fibre prepreg are separately prepared in an autoclave at $120^{\circ} \mathrm{C}$ for $1 \mathrm{~h}$ to identify different decomposition temperature regions of BR 127 and FM 94. Initial mass for each cuboid shaped GLARE, $2024 \mathrm{Al}$ alloy sheet/BR 127 and FM 94/S2-glass fibre prepreg for the thermal decomposition tests in the present study is $60 \mathrm{mg}$. Test shows that the mass fraction of epoxy in GLARE is $10 \%$, i.e., sample contains $6 \mathrm{mg}$ epoxy resins. The size of GLARE scrap for thermal delamination is $50 \mathrm{~mm} \times 35 \mathrm{~mm} \times 4.6 \mathrm{~mm}$ (length $\times$ width $\times$ thickness) with mass of $20 \mathrm{~g}$.

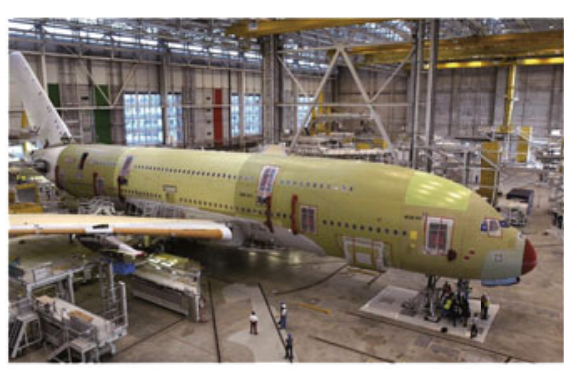

(a) Assembling

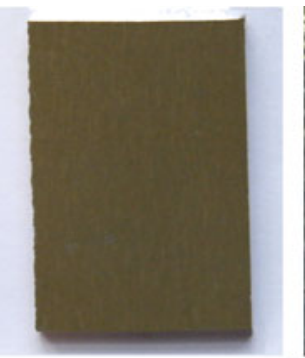

(b) Front view

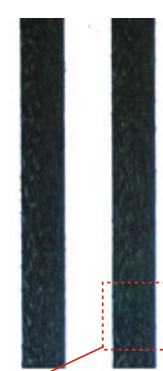

T

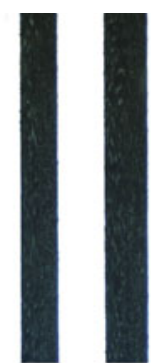

(c) Layered structure
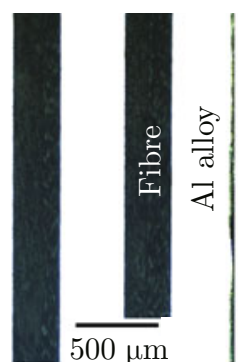

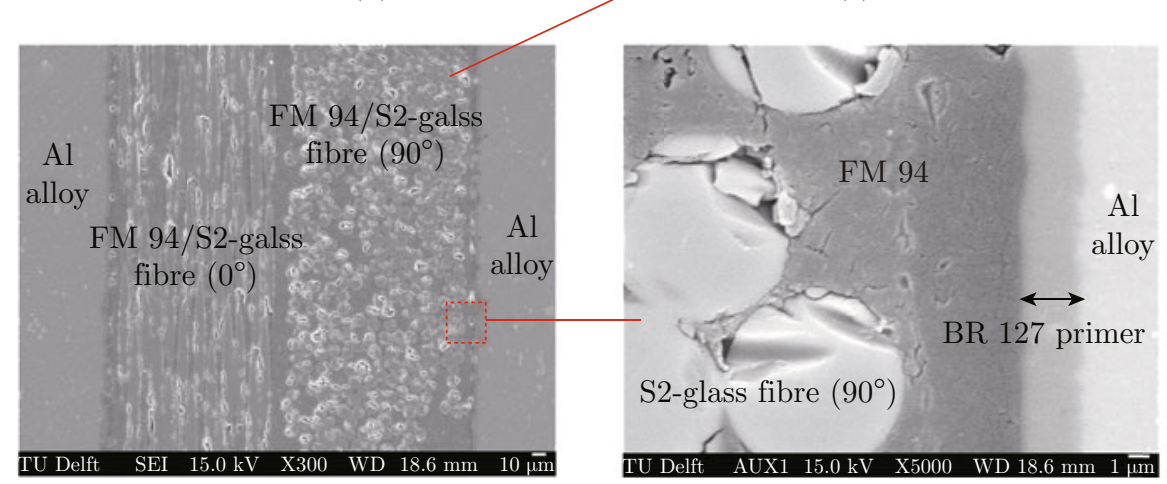

(d) SEM patterns

Fig. 1 Airbus A380 under assembling and new GLARE scrap structure SEM patterns

\subsection{Methods}

All mass change and heat flow curves in the GLARE delamination experiments are obtained using a simultaneous thermal analysis (STA) (STA 409, NETZSCH) of both TGA and DSC in dry nitrogen or air atmosphere at a flow rate of $100 \mathrm{~mL} / \mathrm{min}$. To identify the initial decomposition temperatures of two different commercial epoxy resins during the GLARE delamination, the cured $2024 \mathrm{Al}$ alloy sheet/BR 127 and FM 94/S2glass fibre prepreg are separately heated up to $600^{\circ} \mathrm{C}$ at a heating rate of $5^{\circ} \mathrm{C} / \mathrm{min}$ in nitrogen or air atmosphere. According to the decomposition temperatures of $2024 \mathrm{Al}$ alloy sheet/BR 127 and FM 94/S2-glass fibre prepreg, GLARE samples are heated up from ambient to $600^{\circ} \mathrm{C}$ at a rate of $1,2,5^{\circ} \mathrm{C} / \mathrm{min}$ respectively in nitrogen, but are only heated up from ambient to $500^{\circ} \mathrm{C}$ 
at a rate of $1,2,5^{\circ} \mathrm{C} / \mathrm{min}$ respectively in air atmosphere due to the lower melting start temperature $\left(502^{\circ} \mathrm{C}\right)^{[6]}$ of $2024 \mathrm{Al}$. The decomposition results of $2024 \mathrm{Al}$ alloy sheet/BR 127 and FM 94/S2-glass fibre prepreg indicate that $500^{\circ} \mathrm{C}$ is high enough for the GLARE thermal analysis in air.

The thermal delamination of GLARE scrap with size of $50 \mathrm{~mm} \times 35 \mathrm{~mm} \times 4.6 \mathrm{~mm}$ is carried out in an electric resistance furnace (Carbolite company) under air atmosphere. The furnace is heated up to the given treatment temperature at a heating rate of $15^{\circ} \mathrm{C} / \mathrm{min}$, and time used for heating process is not included in the holding time in this paper.

\section{Results and Discussion}

\subsection{Thermal Analysis}

The non-isothermal DSC tests for GLARE, FM 94/S2-glass fibre prepreg and $2024 \mathrm{Al}$ alloy sheet/BR
127 are separately investigated in nitrogen and air atmospheres to understand the decomposition behaviors of FM 94 and BR 127 during the GLARE delamination. The results are shown in Fig. 2. Considering that the melting point of S2-glass fibre is higher than $600{ }^{\circ} \mathrm{C}$, the heat flows of FM 94/S2-glass fibre prepregs in Fig. 2 are completely caused by the decomposition of FM 94. For the BR 127/2024 Al alloy sheet system, the nominal range of melting temperature of $2024 \mathrm{Al}$ alloy is $502-638^{\circ} \mathrm{C}$, and that is why an endothermic peak occurs at $502{ }^{\circ} \mathrm{C}$. Therefore, the heat flows of $2024 \mathrm{Al}$ alloy sheet/BR 127 are primarily caused by the decomposition of BR 127 when the temperature is lower than $502{ }^{\circ} \mathrm{C}$. The weight change caused by oxidation of 2024 $\mathrm{Al}$ alloy under air atmosphere is negligible when the temperature is lower than $502^{\circ} \mathrm{C}$ because of the protection of the existed $\mathrm{Al}_{2} \mathrm{O}_{3}$ films on the surface of $\mathrm{Al}$ sheets.

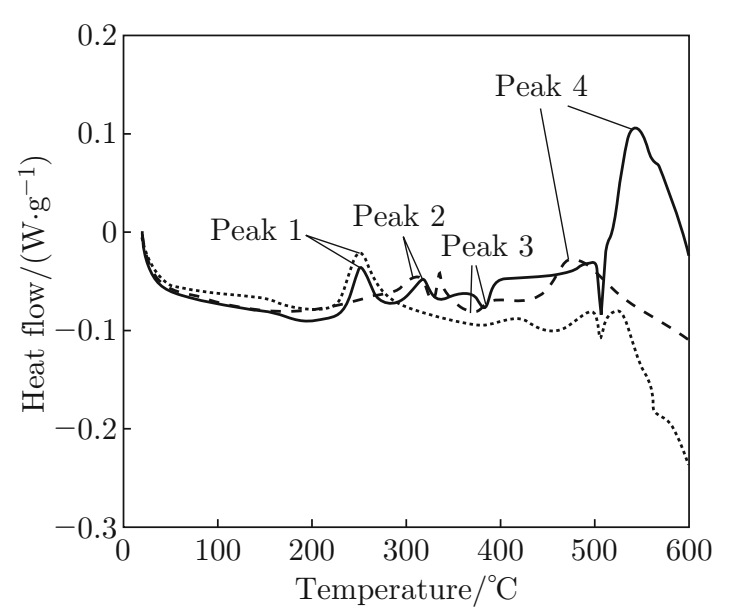

(a) In nitrogen

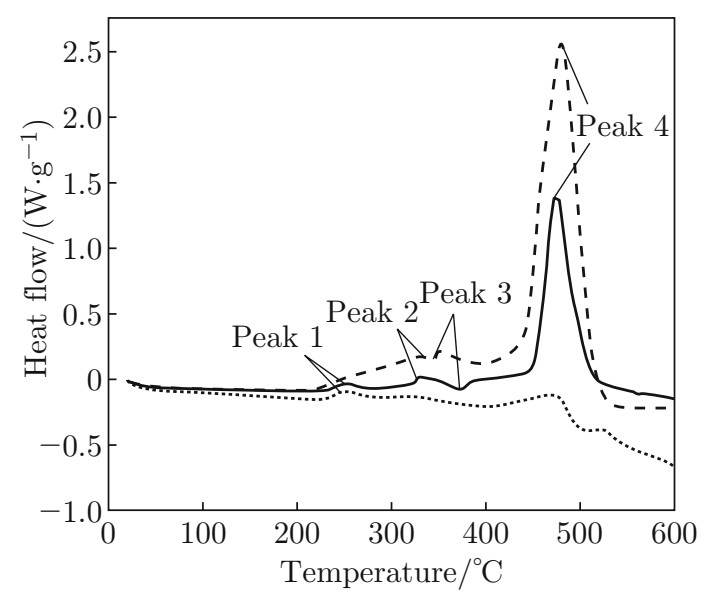

(b) In air

— GLARE, _- - FM 94/S2-glass fibres, _..-.... BR 127/2024 Al alloy

Fig. 2 DSC curves of $60 \mathrm{mg}$ GLARE, $60 \mathrm{mg}$ FM 94/S2-glass fibres prepreg and $60 \mathrm{mg} \mathrm{BR} 127 / 2024 \mathrm{Al}$ alloy in nitrogen and air at the heating rate of $5^{\circ} \mathrm{C} / \mathrm{min}$

Four peaks (excluding the endothermic peak around $502{ }^{\circ} \mathrm{C}$ caused by $\mathrm{Al}$ alloy melting) caused by epoxy decomposition can be observed in the heat flows of GLARE under both nitrogen and air, including three exothermic peaks and one endothermic peak. By comparing the heat flows of GLARE and BR 127 in nitrogen and air atmospheres, it is obvious that the formation of first exothermic peak (Step 1) of GLARE is caused by the decomposition of epoxy BR 127 and the initial decomposition temperature of $\mathrm{BR} 127$ in air is about $225^{\circ} \mathrm{C}$ at the heating rate of $5^{\circ} \mathrm{C} / \mathrm{min}$. One small exothermic peak (Step 2), one endothermic peak (Step 3 ) and one large exothermic peak (Step 4) can be observed in the heat flow curves of FM 94 decomposition under both nitrogen and air atmospheres, especially in air. It is clear that the heat flows of Step 4 in air are more intensive than those in nitrogen. The initial decomposition temperatures of each step of FM 94 are about 290,345 and $410^{\circ} \mathrm{C}$ respectively in air when the heating rate is $5^{\circ} \mathrm{C} / \mathrm{min}$.

Figure 3 shows the mass loss and DSC heat curves of GLARE in the non-isothermal STA tests with different heating rates. With increasing the heating rate, there is no enough time for epoxy resin decomposition due to the low thermal conductivity of GLARE; the decomposition moves to the higher temperature region. The decomposition is more intensive under higher temperature, resulting in higher endothermic or exothermic 
peak height. Final mass loss of GLARE in air at the heating rate of $1{ }^{\circ} \mathrm{C} / \mathrm{min}$ is $10 \%$ which is consistent with the total percentage of epoxy in GLARE, as mentioned before. Thus the conversions (decomposition degree) of epoxy resins under different non-isothermal conditions can be calculated, as shown in Fig. 4.

The conversion of epoxy resins is decreased at higher heating rates when samples are heated up to the same maximum temperature, and this is due to the hysteretic decomposition at a higher heating rate. Moreover, it is obvious that final conversion of epoxy resins in air is higher than that in nitrogen at the same heating rate. Epoxy resin conversions are $75 \%$ and $100 \%$ respectively in nitrogen and air at $500^{\circ} \mathrm{C}$ at the heating rate of $1{ }^{\circ} \mathrm{C} / \mathrm{min}$. The resin decomposition degree is just $90 \%$ though the sample is heated up to $600^{\circ} \mathrm{C}$ in nitrogen at the heating rate of $1{ }^{\circ} \mathrm{C} / \mathrm{min}$. Therefore, oxidative atmosphere should be more beneficial to the epoxy resin decompositions compared with the inert atmosphere.

The details of epoxy decomposition in each step under both atmospheres are also investigated to better understand the influence of heating rate and atmosphere, which are listed in Tables 1 and 2. The Steps in Table 1 are defined according to the heat flows. The mass loss of epoxy resins in Table 2 describes the decomposition degree when the temperature increases from the initial decomposition temperature of this step to the initial decomposition temperature of next step. It should be noticed that all end temperatures for the tests in air are $500^{\circ} \mathrm{C}$ to avoid the influence of drastic oxidation of $\mathrm{Al}$ alloy on heat and mass change. As can be seen in Table 1, the initial decomposition temperatures $t_{\mathrm{i}}$ and

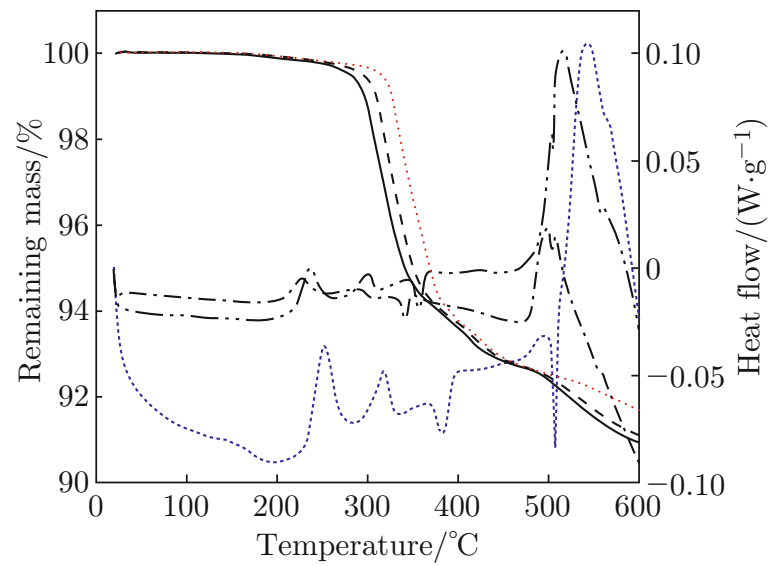

(a) In nitrogen

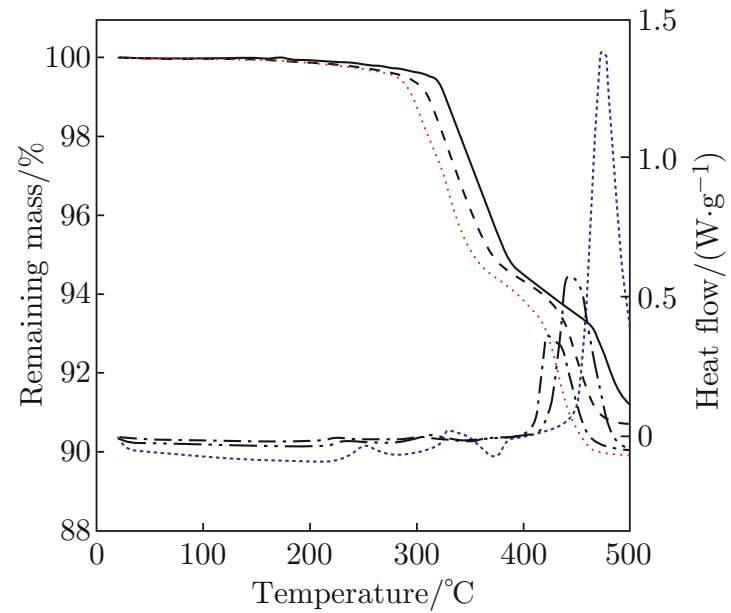

(b) In air

$$
\begin{array}{lll}
\text { - TG } 1{ }^{\circ} \mathrm{C} / \mathrm{min}, & --\mathrm{TG} 2{ }^{\circ} \mathrm{C} / \mathrm{min}, & \ldots . . . . . \\
\text { TG } 5{ }^{\circ} \mathrm{C} / \mathrm{min}
\end{array}
$$

Fig. 3 Remaining mass versus temperature for GLARE delamination at different heating rates in nitrogen and air

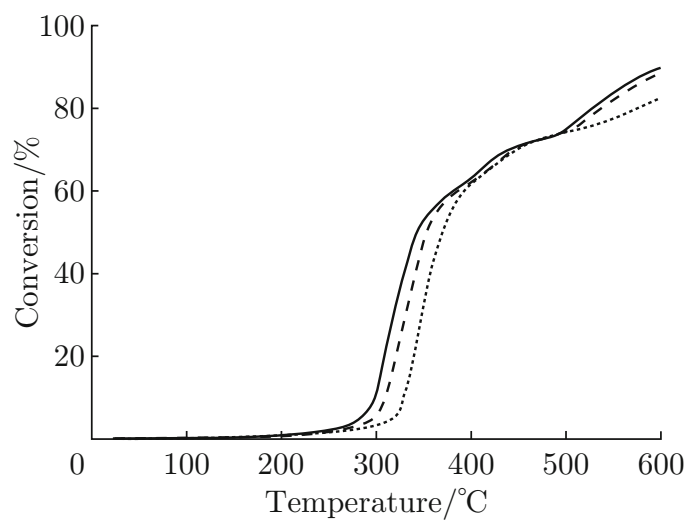

(a) In nitrogen

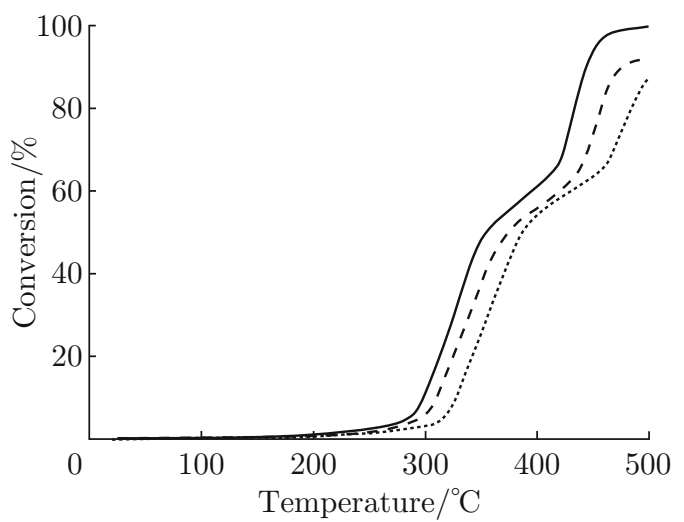

(b) In air

$-1{ }^{\circ} \mathrm{C} / \mathrm{min}, \quad---2{ }^{\circ} \mathrm{C} / \mathrm{min}, \quad \cdots \cdots \cdots \cdot 5^{\circ} \mathrm{C} / \mathrm{min}$

Fig. 4 Conversion versus temperature for resin decompositions at different heating rates in nitrogen and air 
Table 1 Initial decomposition temperatures and temperature at maximum decomposition ratio for each step in the non-isothermal condition in nitrogen and air

\begin{tabular}{|c|c|c|c|c|c|c|c|c|c|}
\hline \multirow{2}{*}{ Atmosphere } & \multirow{2}{*}{$\begin{array}{l}\text { Heating rate/ } \\
\left({ }^{\circ} \mathrm{C} \cdot \min ^{-1}\right)\end{array}$} & \multicolumn{4}{|c|}{$t_{\mathrm{i}} /{ }^{\circ} \mathrm{C}$} & \multicolumn{4}{|c|}{$t_{\mathrm{m}} /{ }^{\circ} \mathrm{C}$} \\
\hline & & Step 1 & Step 2 & Step 3 & Step 4 & Step 1 & Step 2 & Step 3 & Step 4 \\
\hline \multirow[t]{3}{*}{ Nitrogen } & 1 & 188 & 255 & 311 & 354 & 227 & 293 & 341 & 500 \\
\hline & 2 & 210 & 262 & 317 & 368 & 238 & 301 & 356 & 516 \\
\hline & 5 & 223 & 282 & 334 & 406 & 251 & 319 & 380 & 543 \\
\hline \multirow[t]{3}{*}{ Air } & 1 & 188 & 255 & 318 & 356 & 227 & 298 & 326 & 423 \\
\hline & 2 & 212 & 260 & 330 & 388 & 238 & 313 & 344 & 442 \\
\hline & 5 & 225 & 288 & 344 & 408 & 251 & 329 & 371 & 473 \\
\hline
\end{tabular}

Table 2 Mass loss of epoxy resins in each step of decomposition in nitrogen (from 20 to $600{ }^{\circ} \mathrm{C}$ ) and air (from 20 to $500{ }^{\circ} \mathrm{C}$ )

\begin{tabular}{|c|c|c|c|c|c|c|}
\hline \multirow{2}{*}{ Atmosphere } & \multirow{2}{*}{$\begin{array}{l}\text { Heating rate/ } \\
\left({ }^{\circ} \mathrm{C} \min ^{-1}\right)\end{array}$} & \multicolumn{4}{|c|}{ Mass loss $/ \%$} & \multirow[b]{2}{*}{ Total } \\
\hline & & Step 1 & Step 2 & Step 3 & Step 4 & \\
\hline \multirow[t]{3}{*}{ Nitrogen } & 1 & $2.6(188-254)$ & $20.2(255-310)$ & $31.8(311-353)$ & $35.2(354-600)$ & 89.8 \\
\hline & 2 & $2.8(210-261)$ & $14.9(262-316)$ & $39.0(317-367)$ & $31.8(368-600)$ & 88.5 \\
\hline & 5 & $2.8(223-281)$ & $13.5(282-333)$ & $46.6(334-405)$ & $19.8(406-600)$ & 82.7 \\
\hline \multirow[t]{3}{*}{ Air } & 1 & $2.8(188-254)$ & $21.6(255-317)$ & $26.4(318-355)$ & $49.2(356-500)$ & 100.0 \\
\hline & 2 & $2.9(212-259)$ & $20.8(260-329)$ & $30.4(330-387)$ & $38.0(388-500)$ & 92.1 \\
\hline & 5 & $2.8(225-287)$ & $19.5(288-343)$ & $32.5(344-407)$ & $31.9(408-500)$ & 86.7 \\
\hline
\end{tabular}

Note: the numbers in the brackets denote the temperature range, ${ }^{\circ} \mathrm{C}$.

the temperature $t_{\mathrm{m}}$ at the maximum conversion rate of BR 127 (Step 1) are very close in both atmospheres at the same heating rate. Therefore, the decomposition behavior of BR 127 in air should be similar to that in nitrogen under the non-isothermal condition, and just the initial decomposition temperature goes up from 188 to $225^{\circ} \mathrm{C}$ when the heating rate increases from 1 to $5^{\circ} \mathrm{C} / \mathrm{min}$. The decomposition behavior of FM 94 is more complex and it is described in Steps $2-4$ for both atmospheres. All $t_{\mathrm{i}}$ and $t_{\mathrm{m}}$ of Steps $2-4$ are enhanced with increasing the heating rate in both atmospheres. Different with Steps 2 and 4, the mass loss of Step 3 is higher with increasing the heating rate in both atmospheres, and the mass loss of Step 3 in nitrogen is bigger than that in air. However, the total conversion of epoxy resins in air is bigger than that in nitrogen when the same heating rate is employed though the end test temperature in air is $100^{\circ} \mathrm{C}$ lower.

As discussed before, it is obvious that oxidative atmosphere is more preferred for the GLARE delamination. An appropriate holding temperature is important for the GLARE thermal delamination with high efficiency. The holding temperature should be high enough to ensure that the epoxy resins can be completely decomposed at this temperature while avoiding the oxidation of $2024 \mathrm{Al}$ alloy and lowering the energy cost. Based on the previous thermal analysis results of epoxy resin decomposition in air at the slow heating rate of $1^{\circ} \mathrm{C} / \mathrm{min}$, the suitable holding temperature for the GLARE delamination should be located in between 423 (Table 1) and $502{ }^{\circ} \mathrm{C}$.

\subsection{GLARE Delamination}

In order to determine the optimum holding temperature for the GLARE delamination, four different holding temperatures are carried out, 440, 460, 480 and $500^{\circ} \mathrm{C}$ respectively. Plenty of oxidation spots on the $\mathrm{Al}$ sheets are observed when the employed holding temperature is $500{ }^{\circ} \mathrm{C}$. A strong exothermic peak (around $450^{\circ} \mathrm{C}$, Fig. $3(\mathrm{~b})$ ) is found in the DSC curves of GLARE in air which causes the real temperature around the $\mathrm{Al}$ sheet to be higher than the given temperature of $500^{\circ} \mathrm{C}$. Thus the real temperature in the furnace should be close to the $\mathrm{Al}$ start melting point, resulting in oxidation spots. Therefore, $500^{\circ} \mathrm{C}$ is a little too high for the GLARE thermal delamination.

The experimental results indicate that the required holding time for the GLARE complete delamination is 210,150 and $120 \mathrm{~min}$ when the holding temperature is 440,460 and $480^{\circ} \mathrm{C}$ respectively. According to the GLARE delamination results, the appropriate 
delamination process is at the holding temperature of $480^{\circ} \mathrm{C}$ for $120 \mathrm{~min}$.

\section{Conclusion}

In this work, the thermal analysis at elevated temperatures are conducted for studying the decomposition behavior of epoxy resins BR127 and FM 94 in GLARE, which provides the significant information for optimization of the GLARE thermal delamination process parameters.

The results indicate that the decomposition of resins consists of four steps under the non-isothermal conditions, the first step is attributed to the decomposition of epoxy resins (BR 127) coated on the Al alloy sheets, and the later three steps are attributed to the decomposition of binder for glass fibre (FM 94). The initial decomposition temperature of BR 127 and FM 94 is 188 and $255^{\circ} \mathrm{C}$ respectively in both oxidative and inert atmospheres when the heating rate of $1^{\circ} \mathrm{C} / \mathrm{min}$ is employed. The oxidative atmosphere is more beneficial to the epoxy resin decompositions compared with the inert atmosphere. The final conversion of resins in air and nitrogen is $100 \%$ and $89.8 \%$ respectively when the GLARE sample of $60 \mathrm{mg}$ is heated up to $500^{\circ} \mathrm{C}$ in air and $600^{\circ} \mathrm{C}$ in nitrogen at the same heating rate of $1^{\circ} \mathrm{C} / \mathrm{min}$. For GLARE delamination in the industrial scale experiments, the appropriate delamination process is at the holding temperature of $480^{\circ} \mathrm{C}$ for $120 \mathrm{~min}$.
Acknowledgement The authors would like to thank Mr. ZHANG Zhan and Dr. SONG Gui-ming (Department of Materials Science and Engineering, TU Delft) for their supports on STA tests. The authors are also grateful to Mr. MADRUGA Alfonso (Department of Aerospace Materials and Manufacturing, TU Delft) for preparation of $2024 \mathrm{Al}$ alloy foil/BR 127 and FM 94/S2-glass fibre prepregs.

\section{References}

[1] Vlot A, Gunnink J W. Fibre metal laminates: An introduction [M]. Dordrecht: Kluwer Academic Publishers, 2001.

[2] FOKKER. GLARE [EB/OL]. (2011-09-08). http://www.fokker.com/Innovations-GLARE.

[3] Pickering S J. Recycling technologies for thermoset composite materials-current status [J]. Composites Part A, 2006, 37(8): 1206-1215.

[4] Pimenta S, Pinho S T. Recycling carbon fibre reinforced polymers for structural applications: Technology review and market outlook [J]. Waste Management, 2011, 31(2): 378-392.

[5] Alderliesten R C, Homan J J. Fatigue and damage tolerance issues of GLARE in aircraft structures [J]. International Journal of Fatigue, 2006, 28(10): 11161123.

[6] Jen M H R, Sung Y C, Lai Y D. Tensile and fatigue testings of hybrid Al/APC-2 nanocomposite laminates at elevated temperature [J]. Advanced Materials Research, 2008, 47-50: 592-595. 